\title{
Fecal starch as an indicator of total-tract starch digestibility by lactating dairy cows
}

\author{
S. M. Fredin, L. F. Ferraretto, M. S. Akins, ${ }^{1}$ P. C. Hoffman, and R. D. Shaver ${ }^{2}$ \\ Department of Dairy Science, University of Wisconsin-Madison, Madison 53706
}

\begin{abstract}
To test whether total-tract starch digestibility by lactating dairy cattle could be predicted accurately from concentration of starch in fecal dry matter (FS), data from 8 digestibility trials, 30 diets, and 564 individual starch measurements were compiled from trials conducted at the University of Wisconsin-Madison. Total-tract starch digestibility by individual cows was determined from the concentrations of starch in total mixed rations and feces (rectal grab samples) and concentrations of several external or intrinsic feed markers. Fecal starch concentration was closely and linearly related to total-tract starch digestibility $\left(\mathrm{R}^{2}=0.94\right)$. Differences in fecal sampling time for FS, such as day within week or week, did not influence determination of FS concentration. In contrast, time of day when fecal samples were taken influenced FS concentration, but the differences were minimal (mean \pm standard error of the mean $=0.4 \pm 0.1$ ). These data suggest that on-farm collection of feces from individual cows or pens of cows may be sampled only once per day. Fecal $\mathrm{pH}$ was not related to FS when FS was only 1 to $3 \%$, indicating that fecal $\mathrm{pH}$ was not a good index of FS and not practical as a tool to assess total-tract starch digestibility for lactating dairy cows when fecal starch excretion is low. An equation was developed to predict FS using near-infrared reflectance spectroscopy of dried ground fecal samples; the equation had moderate to good accuracy $\left(\mathrm{R}^{2}=0.83-0.94\right)$ and a low standard error of prediction. Fecal starch concentration can be used to monitor total-tract starch digestibility.
\end{abstract}

Key words: digestibility, lactating cow, starch

\section{INTRODUCTION}

Interest in improving starch digestibility by lactating dairy cows has been stimulated by the high cost of cereal grains. An increase in total-tract starch digest-

Received August 20, 2013.

Accepted November 24, 2013.

${ }^{1}$ Current address: School of Agriculture, University of WisconsinPlatteville, Platteville, WI 53711.

${ }^{2}$ Corresponding author: rdshaver@wisc.edu ibility (TTSD) can increase yield of milk and protein and feed efficiency (Firkins et al., 2001). Total-tract digestibility of starch in dairy cows ranges from 70 to 100\% (Firkins et al., 2001; Ferraretto et al., 2013) and is influenced by numerous factors such as particle size, grain processing, and storage method (Firkins et al., 2001; Ferraretto et al., 2013); harvest maturity, moisture content, and duration of silo fermentation (Hoffman et al., 2011; Ferraretto and Shaver, 2012b); and corn endosperm type (Taylor and Allen, 2005; Lopes et al., 2009). Currently, one common method to estimate the amount of starch that escapes digestion is to sieve fecal material and qualitatively estimate the amount of grain caught by the screen (Hall, 2002). Combined with measurements of the dietary starch concentration and in vitro starch digestibility of feedstuffs, such measurements should lead to ration adjustments when the amount of grain found in feces is excessive (Hall, 2002). Commercial laboratories offer a wet chemistry measurement of starch concentration in feces; estimates of starch availability based on enzyme, yeast, or in vitro incubation; and quantitative measurements of total-tract nutrient digestibility, including starch, that require nutrient analysis of TMR and feces.

Fecal starch concentration (FS) proved to be an accurate indicator of TTSD by feedlot cattle (Zinn et al., 2002; Corona et al., 2005), and FS has been used to assess the effectiveness of grain processing (Zinn et al., 2007). Fernandez et al. (1982) first reported a relationship between TTSD and FS for lactating dairy cows. In a literature review, Owens and Zinn (2005) also reported a modest relationship $\left(\mathrm{R}^{2}=0.73\right)$ between FS and TTSD by lactating dairy cows.

More recently, J. D. Ferguson (University of Pennsylvania, Philadelphia, PA; personal communication), as referenced by Grant (2010), reported that TTSD could be estimated from FS in lactating dairy cows on commercial farms from samples of TMR and feces. Starch and lignin concentrations were determined for the TMR and pen fecal composites to calculate TTSD; a negative relationship between FS and TTSD was detected $\left(\mathrm{R}^{2}=0.73\right)$.

Experimental objectives of this research were to (1) develop an equation to estimate TTSD from FS mea- 
sured in controlled research trials; (2) determine the distribution and variation for FS concentrations associated with week, day within week, and time within day of sample collection; (3) examine the relationship between fecal pH and FS; and (4) evaluate the potential for developing a near-infrared reflectance spectroscopy (NIRS) technique and equation for quantifying FS.

\section{MATERIALS AND METHODS}

All experimental procedures and animal use protocols were approved by the Research Animal Resource Committee of the College of Agricultural and Life Sciences of the University of Wisconsin-Madison.

\section{Fecal Starch Equation}

To develop an equation to estimate TTSD from FS, data from 8 trials at the University of WisconsinMadison from 1997 to 2012 were compiled. These trials are described in Table 1. Across all trials, lactating Holstein cows ranged from 29 to 151 DIM at the start of the trials. Cow within each experiment served as the experimental unit except in the trial by Ferraretto et al. (2012), where gate feeders (RIC system, Insentec, Marknesse, the Netherlands; $1.40 \mathrm{~m}$ deep, $0.80 \mathrm{~m}$ wide, and $0.75 \mathrm{~m}$ high; 2 cows per gate) served as the experimental unit. All diets were fed as a TMR with daily DMI for individual cows or gates calculated as feed delivered daily minus daily refusals. Starch intake was corrected for the concentration of starch remaining in the refusals. Fecal grab samples were collected from each cow twice at 1000 and $2200 \mathrm{~h}$ during the last 3 d of each period for Bal et al. (1997) and at 1100 and 2300 h on d 24 through 26 for Schwab et al. (2002); or thrice at 1000, 1600, and $2200 \mathrm{~h}$ during the last $3 \mathrm{~d}$ of each period for Bal et al. (2000a) and at 0800, 1400, and $2000 \mathrm{~h}$ during the last $3 \mathrm{~d}$ of each period for Bal et al. (2000b). Six fecal grab samples were collected at 8-h intervals covering each 4 -h clock period over 3 consecutive days during each period for Lopes et al. (2009), or during wk 8 of the treatment period for Gencoglu et al. (2010), or during wk 4 and 8 of the treatment period for Ferraretto et al. (2012). For all trials, TMR and fecal samples were dried at $60^{\circ} \mathrm{C}$ for 48 to $72 \mathrm{~h}$ in a forced-air oven and ground through a 1-mm screen with a Wiley mill (Arthur H. Thomas, Philadelphia, PA; Bal et al., 1997). To calculate digestibility from concentrations of nutrients in the TMR and feces, external or intrinsic marker techniques were employed (Table 1). Analysis of starch, rare-earth markers, lignin, and indigestible NDF were conducted as described in the individual papers. Apparent TTSD for each cow fed each diet in each period was calculated using the following equation (Bal et al., 1997):

$$
\begin{gathered}
\text { Apparent TTSD }(\% \text { of DM })=1-[(\text { TMR marker } \\
\text { concentration/fecal marker concentration }) \\
\times(\text { FS concentration/TMR starch concentration })]
\end{gathered}
$$

The distribution of FS was determined using data from 15 trials conducted at the University of Wisconsin-Madison from 1997 to 2012. Trials included in the distribution plot were the 8 trials used to determine the TTSD equation, plus Ferraretto and Shaver (2012a), Akins et al. (2014), and 6 unpublished trials (Arndt et al., 2009; Ferraretto and Shaver, 2013; Fredin et al., 2013a,b; Lopes et al., 2013a,b). Distribution data included cow, gate, or pen as the experimental unit with samples obtained from continuous-lactation or Latin square trials. Fecal grab sampling methods and TTSD calculations for all trials were similar to procedures described previously. Starch concentration in feces was analyzed as described by Ferraretto et al. (2012) for the experiments by Ferraretto and Shaver (2012a), Akins et al. (2014), and the 6 unpublished trials (Arndt et al., 2009; Ferraretto and Shaver, 2013; Fredin et al., 2013a,b; Lopes et al., 2013a,b).

\section{Fecal Starch Sampling Variation}

The effect of fecal sampling time on FS for day within week, week, and time within day was determined within a trial conducted in our laboratory (Akins et al., 2014). One-hundred twenty-eight cows stratified by DIM $(90 \pm 33$ DIM), breed (Holstein and Holstein $\times$ Jersey crossbred), and parity (primi- and multiparous) were assigned randomly to 1 of 16 pens with 8 cows per pen in the University of Wisconsin sand-bedded freestall barn (Emmons Blaine Dairy Research Center, Arlington, WI). Each pen contained 3 primiparous Holstein, 3 multiparous Holstein, and 2 multiparous Holstein $\times$ Jersey crossbred cows that were used in a continuous-lactation trial with a 4 -wk covariate period followed by a 12 -wk treatment period. All cows received the same diet during the covariate period followed by a change to 1 of 4 treatment diets during the test period. Diets were fed once daily as a TMR. Pens were supplied with TMR to allow 5\% refusals, with daily DMI determined on a pen basis throughout the trial. Daily pen refusals were recorded and removed each morning before delivery of fresh feed. Fecal samples were collected just before feeding $(0 \mathrm{~h})$ and $12 \mathrm{~h}$ postfeeding during the last $2 \mathrm{~d}$ of the covariate period and in $\mathrm{wk}$ 6 and 12 of the treatment period. Fecal samples were 


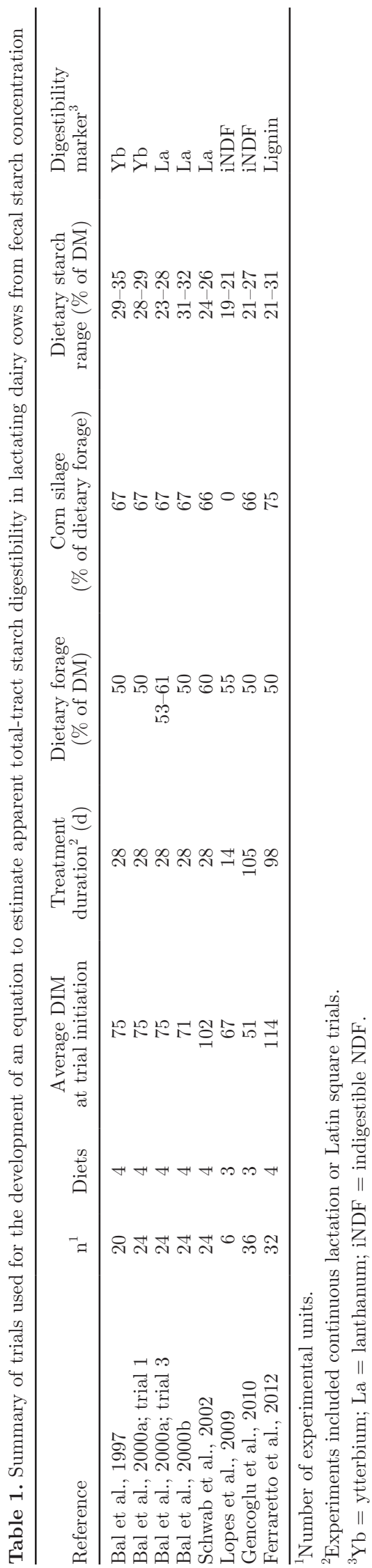

collected from each cow in each pen by rectal grab and composited on a wet volume basis by pen.

\section{Fecal pH}

The relationship between FS and fecal $\mathrm{pH}$ was determined from 2 previous trials from our laboratory conducted in the University of Wisconsin sand-bedded freestall barn (Emmons Blaine Dairy Research Center, Arlington, WI). In the first trial (Ferraretto and Shaver, 2012a), 112 cows were stratified by DIM (116 \pm 36 DIM), breed (Holstein and Holstein $\times$ Jersey crossbred), and parity (primi- and multiparous), and assigned randomly to 1 of 14 pens with 8 cows per pen. Pens were assigned randomly to 1 of 2 treatments in a continuous lactation feeding trial with a 2 -wk covariate period, when cows were fed a single diet, followed by an 8 -wk treatment period, when cows were fed 1 of 2 assigned treatment diets. Likewise, in the second trial (Ferraretto and Shaver, 2013), 112 cows stratified by DIM (139 \pm 47 DIM) and parity (primi- and multiparous) were assigned randomly to 1 of 14 pens with 8 cows per pen. Pens were assigned randomly to 1 of 2 treatments in a continuous-lactation feeding trial with a 2 -wk covariate period, with cows fed a single diet followed by a 10 -wk treatment period with cows fed 1 of 2 treatment diets. In both trials, pens were supplied with TMR to allow for $5 \%$ refusals, with daily DMI determined on a pen basis throughout the trial. Daily pen refusals were recorded each morning before delivery of fresh feed. Fecal samples were collected 4 to $6 \mathrm{~h}$ postfeeding during the last day of wk 5 and 8 or wk 5 and 9 of the treatment period for the first and second trials, respectively. Fecal samples were collected from each cow in each pen by rectal grab and composited on a wet volume basis by pen. For fecal $\mathrm{pH}$ measurements, as described by Gressley and Armentano (2005), approximately $50 \mathrm{~g}$ of fresh feces and $25 \mathrm{~g}$ of distilled water were placed in a specimen cup. The cup was shaken for $20 \mathrm{~s}$ in a vortex, liquids were squeezed through cheesecloth, and the $\mathrm{pH}$ of the liquids was determined with a Cardy Twin $\mathrm{pH}$ meter (model B-213, Spectrum Technologies Inc., Plainfield, IL).

\section{NIRS Equation}

To test the potential for optical methods to quantify FS, NIRS scans were obtained from 295 fecal samples, 238 samples from 3 trials previously conducted at the University of Wisconsin-Madison (Ferraretto and Shaver, 2012a, 2013; Akins et al., 2014), and 57 additional samples obtained from Rock River Laboratory (Watertown, WI). Fecal samples from Rock River Laboratory were added to increase the number of samples that 
had $>5 \%$ FS. All fecal samples from the University of Wisconsin-Madison were dried and ground to pass a 1-mm Wiley mill screen, with fecal starch content determined as described previously. The samples from Rock River Laboratory were ground to pass through a 1-mm screen with a Udy mill (Udy Corp., Boulder, $\mathrm{CO})$. Each fecal sample was packed into a cylindrical sample holder equipped with a quartz window and scanned between 400 and 2,498 $\mathrm{nm}$, as described by Mentink et al. (2006), using an NIRS (model 6500; Foss-NIR System, Silver Spring, MD). Spectra were retained for statistical analysis.

\section{Statistics}

The REG procedure of SAS (version 9.2; SAS Institute Inc., Cary, NC) was used to analyze the relationship between FS and TTSD or fecal pH. To determine if a mean or linear bias was present in the regression model, the residuals (observed - predicted) were evaluated against predicted values centered at the mean (StPierre, 2003). Due to the presence of heteroscedasticity in the regression model for FS and TTSD, a default heteroscedasticity-consistent matrix estimator was included by adding the WHITE option to the MODEL statement to include heteroscedasticity-consistent standard errors (White, 1980). Fecal starch variation data (Akins et al., 2014) were analyzed as a completely randomized design using Proc MIXED with the data from the preliminary period being used as a covariate and week as a repeated measure using the first-order autoregressive covariance structure, which provided the best fit according to Sawa's Bayesian information criterion. The model included day, sampling time, week, and their interactions as fixed effects, and pen as a random effect. Degrees of freedom were calculated using the Kenward-Roger option. Data are reported as least squares means. All statistical significance and trends were declared to be significant at $P \leq 0.05$ and a trend when $P>0.05$ to $P \leq 0.10$, respectively.

Near-infrared reflectance spectroscopy calibrations were developed using WinISI software (version 3.0; Infrasoft International LLC, State College, PA). Calibrations for FS using NIRS were developed using various math transformations and a different number of coefficients in the models as defined by Shenk and Westerhaus (1991a). Calibration performance was evaluated using cross validation procedures (Shenk and Westerhaus, 1991b) in which the calibration coefficient of determination and prediction error was challenged by dividing the calibration samples into 4 subsets of equal size, one subset being reserved for validation and the remaining subsets being used for calibration. Strength of the calibration was based on the cross-validation coefficient of determination $\left(\mathrm{R}^{2}\right)$, the standard error of performance (SEP) corrected for bias, and the mean bias.

\section{RESULTS AND DISCUSSION}

\section{Fecal Starch Equation and Variation}

The trials used to predict TTSD from FS are described in Table 1. Forages used in the trials were alfalfa silage $(\mathrm{n}=1)$ or corn silage and alfalfa silage (n $=7$ ). The mean dietary starch concentration across all experiments was $27 \%$ of DM (range $=19-35 \%$ ). Mean $\mathrm{CP}$ and NDF concentrations (data not presented) were $17 \%$ (range $=15-20 \%$ ) and $28 \%$ of DM (range $=23-37 \%$ ), respectively. This wide range in dietary nutrient composition indicates that the data set should provide a robust equation to estimate TTSD from FS concentration.

The relationship between FS concentration and TTSD is presented in Figure 1A. We observed a strong linear relationship between TTSD and FS: TTSD $\%=$ $100.0 \%-(1.25 \times \mathrm{FS} \%) ; \mathrm{R}^{2}=0.94 ; P<0.001$. Fernandez et al. (1982) predicted TTSD from FS for lactating cows fed high-starch diets (mean $=34 \%$ of DM) in which sorghum grain and silage were the only starch sources; FS\% $=59.9 \%-(0.55 \times$ TTSD $\%) ; \mathrm{R}^{2}=0.64$. Rearranging terms, this equation becomes TTSD\% $=108.8 \%-(1.82 \times \mathrm{FS} \%)$. The greater mean starch concentration of the diets in the trial by Fernandez et al. (1982) likely resulted in a TTSD estimate from FS that was lower than observed in the present study. The residuals (observed - predicted) were plotted against centered predicted TTSD values to determine if a mean or linear bias was present in the regression model (Figure 1B). The mean predicted value used to center the data was 93.5. The mean bias and slope bias were nonsignificant, indicating that FS can be used to accurately predict TTSD.

The relationship observed in the present study is comparable with estimates of TTSD in dairy cows by Owens and Zinn (2005), where TTSD\% $=98.2 \%-(0.93$ $\times \mathrm{FS} \%) ; \mathrm{R}^{2}=0.73$. The relationship is also comparable with estimates of TTSD by steers fed whole, ground, and steam-flaked corn $\left(\mathrm{R}^{2}=0.97\right.$, Corona et al., 2005; $\mathrm{R}^{2}=0.96$, Zinn et al., 2007). However, the slope of the equation in the present study was not as steep as in the equation presented in Grant (2010) for dairy cows, where TTSD $\%=98.7-(1.76 \times \mathrm{FS} \%) ; \mathrm{R}^{2}=$ 0.78. The relationship described in Grant (2010) was developed from a data set containing 72 samples from lactating and dry cows collected from 8 farms. A lower measured TTSD may have resulted in steepness of the slope for the relationship between FS and TTSD. This 


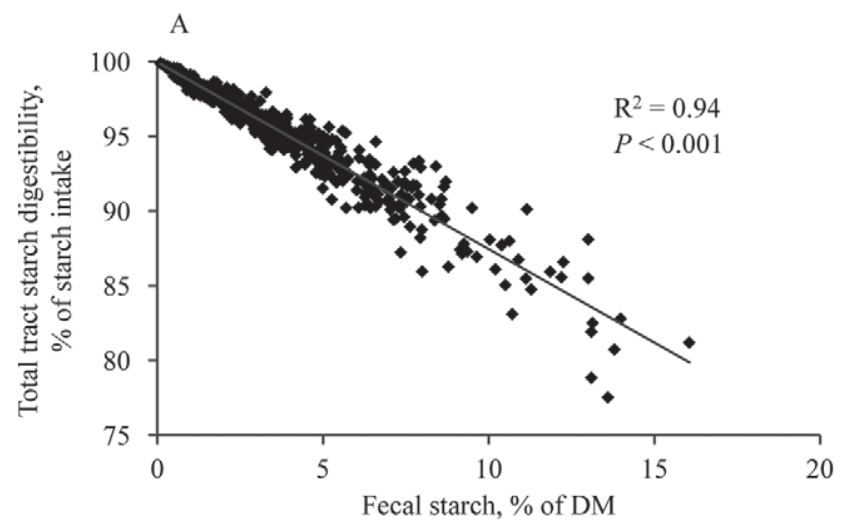

B

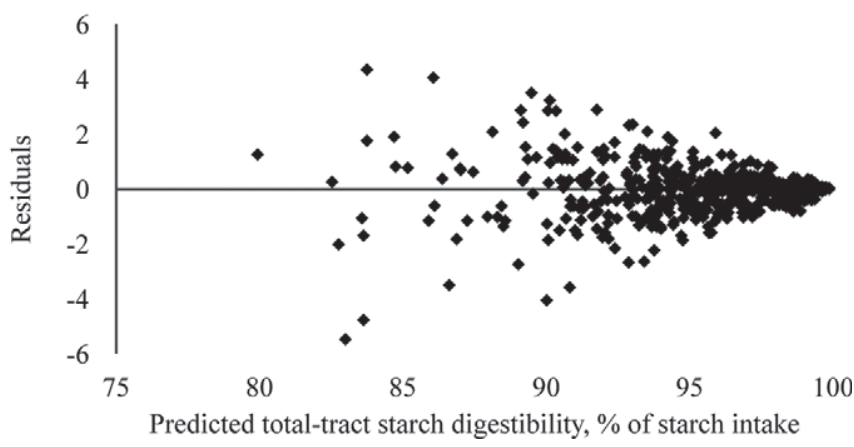

Figure 1. Regression plot of fecal starch (\% of DM) and total-tract starch digestibility (\% of starch intake) for individual cows. (A) Totaltract starch digestibility $\%=100.0 \%( \pm 0.07)-1.25( \pm 0.03) \times$ fecal starch \%; root mean square error $(\mathrm{RMSE})=0.936, \mathrm{R}^{2}=0.94, P<$ $0.001, \mathrm{n}=564 ;(\mathrm{B})$ plot of the residuals: $\mathrm{Y}=-0.05( \pm 0.04)+0.00$ $( \pm 0.01) \times(\mathrm{X}-93.5) ; \mathrm{RMSE}=0.94, \mathrm{R}^{2}=0.00, P=0.93, \mathrm{n}=564$.

may have occurred through dilution of FS due to a greater dietary NDF content of the diet, a lower NDF digestibility, or both.

Fecal starch concentration accounted for $94 \%$ of the variation in TTSD in the present study. It is unlikely that total-tract digestibilities of other nutrients are related as directly to their concentrations in feces. For example, based on a subset of the TTSD data in the present study, where measurements of total-tract NDF digestibility were available, the calculated correlation coefficient for the relationship between total-tract NDF digestibility and fecal NDF concentration was low: total-tract NDF digestibility $=100.0-(1.26 \times$ fecal $\mathrm{NDF} \%$ ); $\mathrm{R}^{2}=0.18 ; \mathrm{n}=390$ (data not provided in figure). Total-tract digestibility of NDF was not well predicted from fecal NDF concentration. Total-tract digestibility of $\mathrm{CP}$ and fat would be under-predicted from fecal concentrations of $\mathrm{CP}$ and fat because of the contribution of endogenous and microbial synthesis of these 2 nutrients. Although NDF is not synthesized endogenously or by microbes, NDF has a lower total-tract digestibility than starch (NRC, 2001). In the present study, fecal starch content was typically 0 to $5 \%$, and
TTSD was typically greater than $95 \%$, resulting in most observations of TTSD occurring at or near the y-intercept (100\% TTSD digestibility). This resulted in a low coefficient of variation for FS at or near the intercept, where most of the observations occur. Because NDF is not as digestible as starch, the coefficient of variation of fecal NDF concentration was rather high and the relationship of total-tract NDF digestibility to fecal NDF concentration was quite poor.

The distribution of FS observed in collective studies is presented in Figure 2. Fecal starch averaged 3\% across all trials, with $60 \%$ of the fecal samples ranging from 0 to $3 \%$ starch. In the data set used to develop the aforementioned TTSD equation, $48 \%$ of the samples ranged from 0 to $3 \% \mathrm{FS}$. Although the data from the 8 trials used to create the TTSD equation are represented in the distribution data set, observations ranging from 0 to $3 \%$ FS are underrepresented in the TTSD equation. To determine if the underrepresentation of samples ranging from 0 to $3 \%$ FS statistically enhanced the TTSD equation, 119 samples with $>3 \%$ FS were chosen, at random, and excluded from the data set. This resulted in $61 \%$ of the new data set ranging from 0 to $3 \% \mathrm{FS}$, similar to the percentage of observations in the distribution plot. The resulting regression equation was unaffected: TTSD $\%=99.9-(1.24 \times \mathrm{FS} \%) ; \mathrm{R}^{2}=$ 0.94 , suggesting that the original equation was not altered by the smaller number of samples that contained 0 to $3 \%$ FS.

\section{Fecal Starch Sampling Variation}

The effect of sampling time on FS concentration for day within week, week, and time within day are presented in Figure 3. Fecal starch concentration was unaffected by sampling day within week $(P=0.14)$ or by week $(P=0.11)$. However, FS was greater in samples collected $0 \mathrm{~h}$ postfeeding compared with 12 $\mathrm{h}$ postfeeding (2.0 vs. $1.6 \%$; $\mathrm{SE}=0.11 ; P<0.01)$, although the numerical difference was small (0.4 percentage units). We observed an effect for the interaction between fecal collection time and day of sampling on FS (Figure 4; $P<0.01$ ). Fecal starch concentration decreased $12 \mathrm{~h}$ postfeeding compared with samples collected just before feeding $(0 \mathrm{~h})$ on 3 of $4 \mathrm{~d}$, but increased on one of the days. Leonard et al. (1989) measured FS over 3 time courses $(0-8,8-16$, and $16-24$ h) after $1 \mathrm{~d}$ of total fecal collection from Angus steers (6 steers per treatment) fed hay with ground corn once per day. Fecal starch concentration (mean $\pm \mathrm{SE}$ ) was $7.8 \pm 1.9,4.8 \pm 1.1$, and $10.3 \pm 2.0 \%$ for $0-8,8-16$, and 16-24 h, respectively. Average FS over $24 \mathrm{~h}$ was $7.6 \pm$ $1.2 \%$. Statistical analysis on the effect of sampling time within day for differences in FS was not performed in 


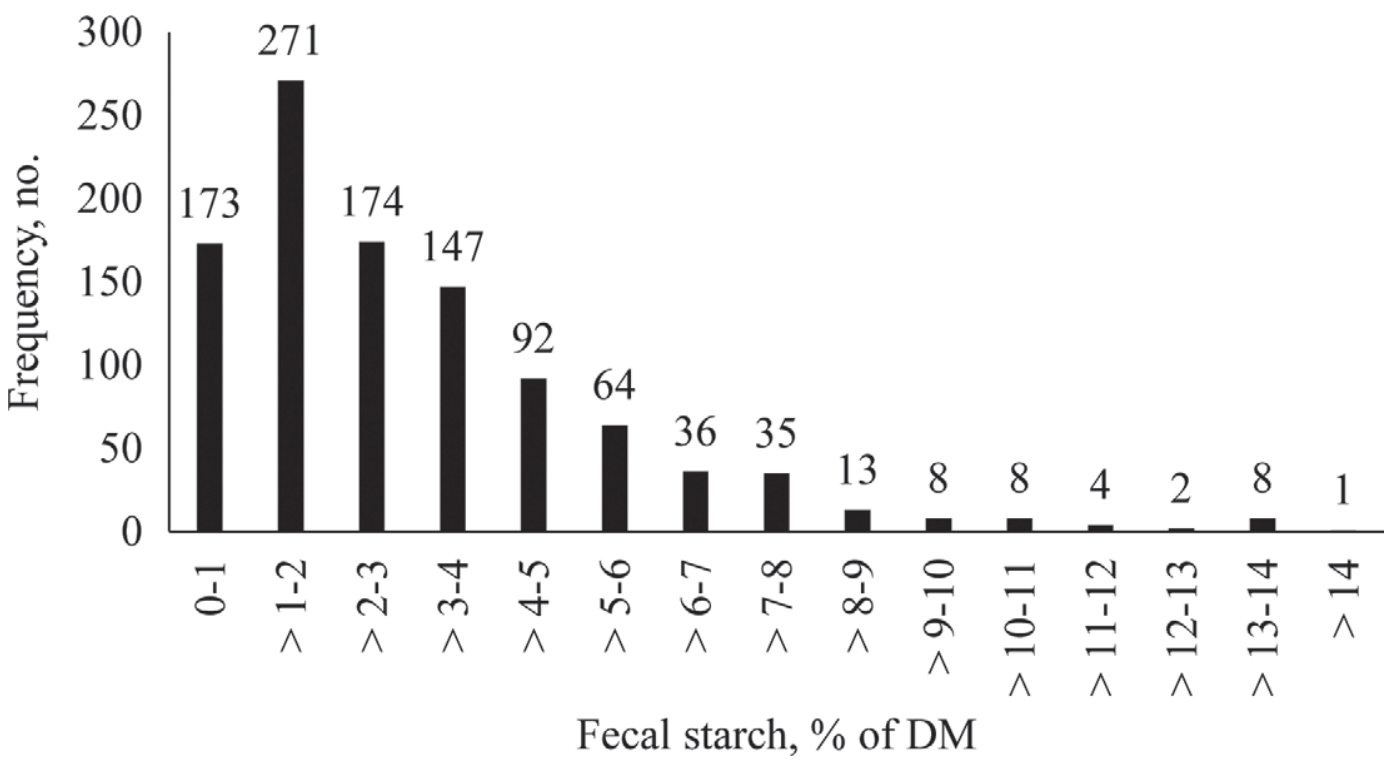

Figure 2. Histogram of fecal starch as a percentage of DM, collected from 15 trials conducted at the University of Wisconsin-Madison; mean $=3.1 ;$ minimum $=0.1 ;$ maximum $=16.1 ; \mathrm{n}=1,036$. The frequency of observations is listed above for each range.

that experiment. In the trial by Leonard et al. (1989), FS appeared to vary during a day. However, because a greater amount of corn grain was fed to their steers (31\% of DMI), FS was increased. Observations from the present study, where TTSD was high (mean = $97 \%$ ), indicate that differences in FS may occur over the course of one day, but that these differences were numerically small. Therefore, a single time point with multiple cows sampled should be suitable for fecal collections on farms to determine TTSD for routine monitoring or diagnostic purposes. Further research may be warranted to determine if a lower TTSD increases the variability of FS during a single day.

\section{Fecal pH}

We found no relationship (data not provided in figure) between FS and fecal $\mathrm{pH}$ within either trial 1 (FS $=1.5 ; P>0.10 ; \mathrm{R}^{2}<0.01 ;$ Ferraretto and Shaver, $2012 \mathrm{a})$ or $2\left(\mathrm{FS}=3.0 ; P>0.10 ; \mathrm{R}^{2}<0.14\right.$; Ferraretto and Shaver, 2013) of this study. The published literature is inconsistent in regards to this relationship. For example, Wheeler and Noller (1976) observed that lower fecal $\mathrm{pH}$ coincided with higher FS concentrations in growing heifers and lactating dairy cows. Likewise, a strong negative relationship between FS and fecal $\mathrm{pH}$ was observed for steers and sheep (Wheeler and Noller, 1977). Others have observed either no relationship (Erdman et al., 1982; Fernandez et al., 1982, experiment 3), a slight relationship (Erdman et al., 1980; Kilmer et al., 1980, 1981), or an intermediate relationship (Fernandez et al., 1982, experiment 1; Ire-
land-Perry and Stallings, 1993) between FS and fecal $\mathrm{pH}$ in dairy cows. Fecal $\mathrm{pH}$ can be affected by factors other than starch, including dietary buffers, buffering capacity of forages, dietary forage concentration, and ruminal acidosis (Erdman et al., 1982; Nocek et al., 1983; Gressley et al., 2011). Gressley et al. (2011), in a recent review of the literature, suggested that hindgut acidosis caused by starch is a function of the amount of starch $(\mathrm{kg} / \mathrm{d})$ flowing to the large intestine and its rate of fermentation. In Ferraretto and Shaver (2012a), approximately $69 \%$ of the starch was from processed corn silage, whereas in Ferraretto and Shaver (2013), approximately $76 \%$ of the starch was from processed corn silage and high-moisture corn. Processed corn silage and high-moisture corn characteristically have high ruminal starch digestion (Ferraretto and Shaver, 2012b; Ferraretto et al., 2013). Abomasal infusions of large doses of starch $(\sim 4 \mathrm{~kg} / \mathrm{d})$ induced decreased fecal pH (Gressley et al., 2011), and consequently, the amount of starch flowing to the large intestine in the present study may have been inadequate to increase cecal fermentation to cause a decrease in fecal $\mathrm{pH}$. Under the conditions of present experiments, when FS was $1.5 \%$ in Ferraretto and Shaver (2012a), and 3.0\% in Ferraretto and Shaver (2013), fecal pH was not reliable as an indicator of FS and thereby not practical as a tool to assess TTSD by dairy cows. These findings are in agreement with Fernandez et al. (1982), who also reported a weak relationship between fecal $\mathrm{pH}$ and TTSD in either dry or lactating dairy cows where FS excretion was much greater compared with that in the current study $($ mean $=10.2 \%$ FS $)$. 

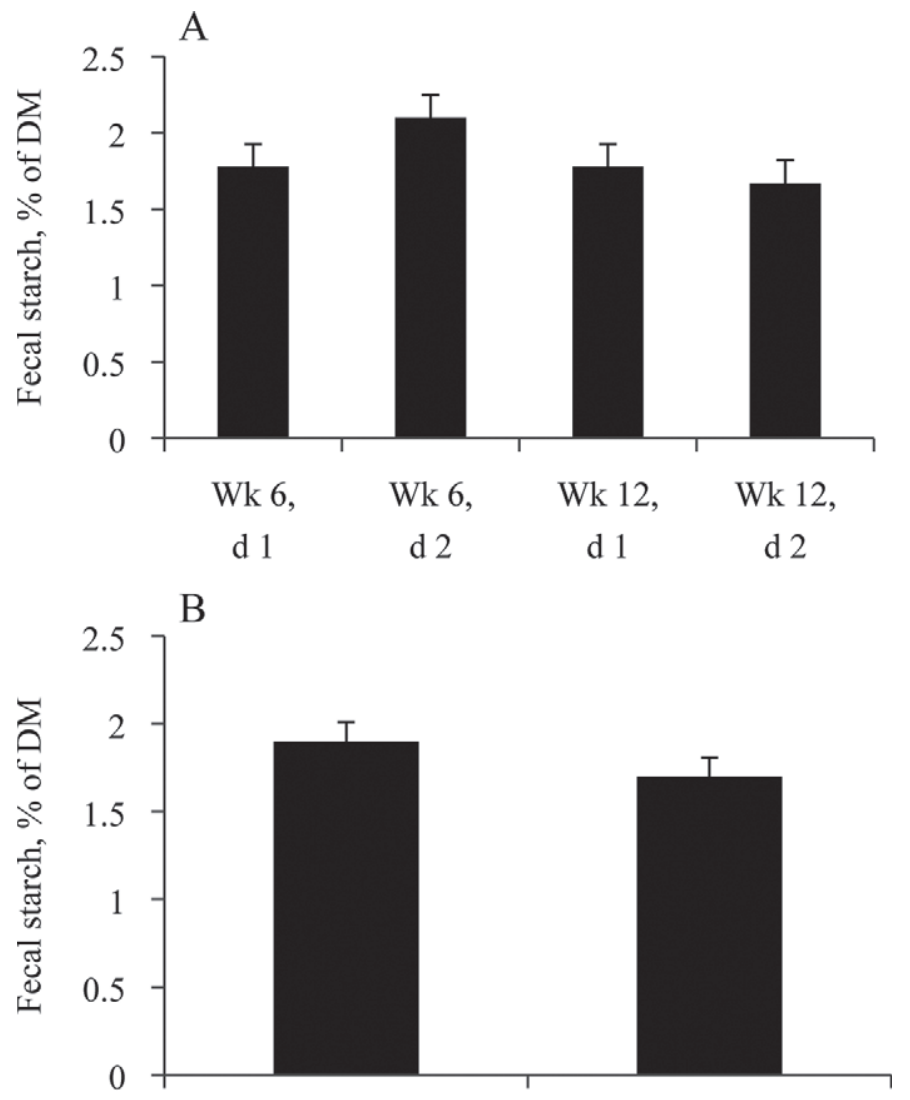

Wk 6

Wk 12

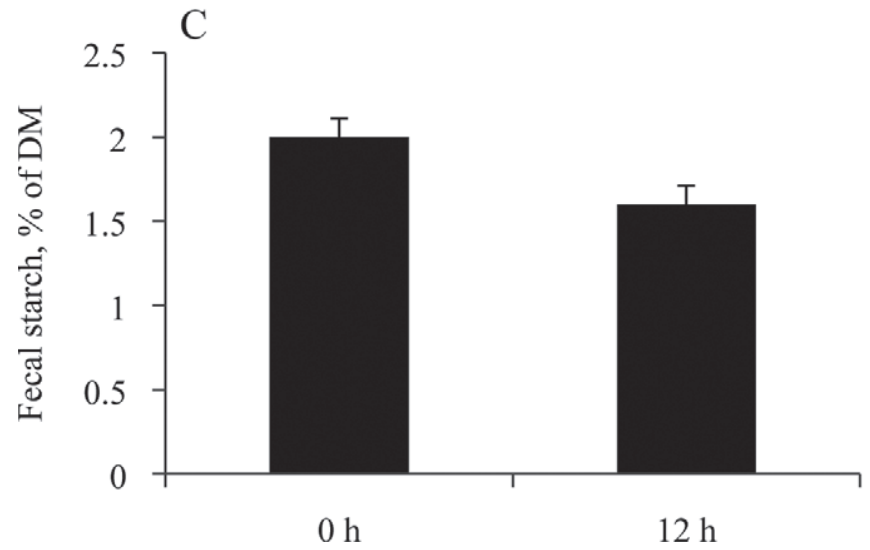

Figure 3. Effect of fecal sampling day, week, and time on fecal starch concentration (\% of DM). (A) Fecal sampling by week and day: $\mathrm{SEM}=0.15, P=0.14 ;(\mathrm{B})$ Fecal sampling by week: $\mathrm{SEM}=0.11, P$ $=0.11 ;(\mathrm{C})$ fecal sampling by time of day postfeeding: $\mathrm{SEM}=0.11$, $P<0.01$.

\section{NIRS Equation}

Near-infrared spectroscopy calibration and crossvalidation statistics of FS predictions are presented in Table 2. Fecal starch concentration was predicted by NIRS with good accuracy for all math transformations except for 2, 2, 2, 1. Combined, simple 1, 4, 4,

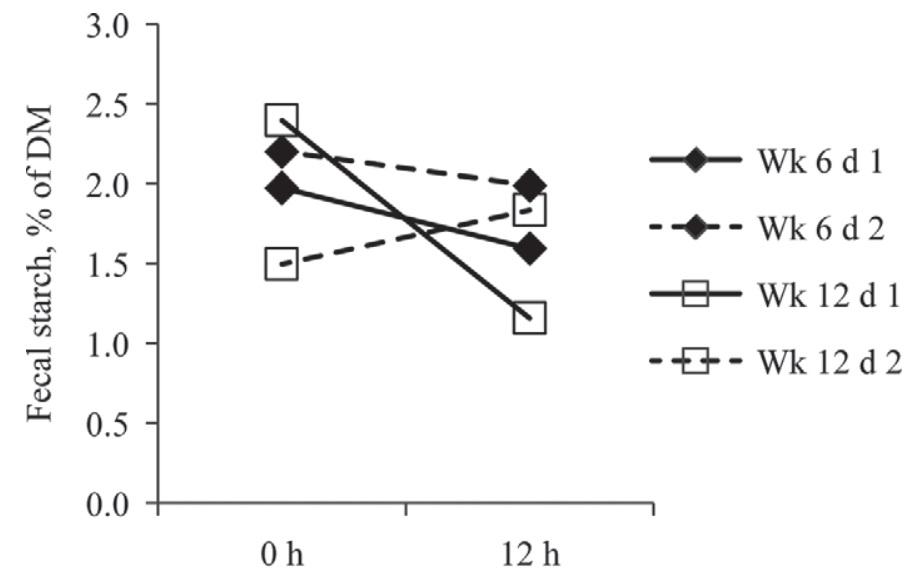

Fecal sample collection postfeeding, $\mathrm{h}$

Figure 4. Effect of fecal sample collection time on fecal starch concentration (\% of DM). Fecal samples were collected just before feeding at $0 \mathrm{~h}$ or $12 \mathrm{~h}$ postfeeding on wk $6(\checkmark)$ and $12(\square)$ for 2 consecutive days. Time $\times$ day interaction $=P<0.01, \mathrm{SEM}=0.18$. Time $\times$ week $\times$ day interaction $=P<0.01, \mathrm{SEM}=0.25$.

1 math transformations yielded a robust coefficient of determination $\left(\mathrm{R}^{2}=0.94\right)$ and a low standard error of calibration $(\mathbf{S E C}=0.45)$ for predicting FS. Cross validation statistics indicated that NIRS calibrations for FS were robust and remained largely unaltered when cross validated. The coefficients of determinations for calibration and cross validation were similar $\left(\mathrm{R}^{2}=\right.$ 0.94 vs. 0.91 ) for the $1,4,4,1$ math transformations. Likewise, SEC and SEP were similar at 0.45 and 0.57 . The relationship between FS and NIRS-determined FS using the 1, 4, 4, 1 transformation was predicted with good accuracy for all samples: NIRS-predicted FS\% = $0.4+(0.07 \times$ FS\% $) ; \mathrm{R}^{2}=0.88 ; P<0.001 ;$ Figure $5 \mathrm{~A}$. The coefficient of determination $\left(\mathrm{R}^{2}=0.88\right)$ presented in Figure 5A is lower than the cross-validation coefficient of determination $\left(\mathrm{R}^{2}=0.92\right)$ for the $1,4,4,1$ transformation reported in Table 2 because 23 outlying observations were omitted during the calibration process; the residuals are plotted in Figure 5B. The mean predicted value used to center the data was 2.99 . The mean bias and slope bias were nonsignificant, indicating that NIRS can be used to accurately predict FS. The omitted observations were left in Figure 5A and $\mathrm{B}$ to demonstrate that NIRS accurately predicted FS when FS is from 0 to $5 \%$. However, when assayed FS was greater than $5 \%$, FS tended to be poorly predicted by NIRS. More samples greater than 5\% FS need to be added to the NIRS sample set to improve this prediction when FS is high or when TTSD is lower than samples included in this sample set.

Starch is routinely predicted by NIRS in forages and TMR with high accuracy and precision (Barrière et al., 2004; Mentink et al., 2006). Most research on rumi- 
Table 2. Calibration and cross-validation statistics for near-infrared reflectance spectroscopy analysis of fecal starch

\begin{tabular}{|c|c|c|c|c|c|c|}
\hline \multirow[b]{2}{*}{ Transformation $^{1}$} & \multicolumn{3}{|c|}{ Calibration } & \multirow[b]{2}{*}{$\mathrm{R}^{2}$} & \multicolumn{2}{|c|}{ Cross-validation } \\
\hline & $\mathrm{n}$ & $\begin{array}{l}\text { Starch, } \\
\% \text { of DM }\end{array}$ & $\mathrm{SEC}^{2}$ & & $\mathrm{R}^{2}$ & $\mathrm{SEP}^{3}$ \\
\hline $1,4,4,1$ & 312 & 2.69 & 0.45 & 0.94 & 0.91 & 0.57 \\
\hline $1,2,2,1$ & 316 & 2.76 & 0.45 & 0.95 & 0.90 & 0.64 \\
\hline $1,10,10,1$ & 317 & 2.84 & 0.50 & 0.95 & 0.94 & 0.58 \\
\hline $2,4,4,1$ & 320 & 2.76 & 0.45 & 0.95 & 0.90 & 0.63 \\
\hline $2,2,2,1$ & 319 & 2.72 & 0.54 & 0.92 & 0.83 & 0.78 \\
\hline $2,10,10,1$ & 316 & 2.71 & 0.49 & 0.94 & 0.91 & 0.60 \\
\hline
\end{tabular}

${ }^{1}$ Spectral math transformation values equal order of derivative function, gap width, segment length of first smoothing, and segment length of second smoothing. Second smoothing of spectra was not conducted; therefore, all values are 1

${ }^{2} \mathrm{SEC}=$ standard error of calibration.

${ }^{3} \mathrm{SEP}=$ standard error of prediction.

nant animals regarding fecal nutrient NIRS predictions has focused on predicting dietary nutrient composition from feces (Lyons and Stuth, 1992; Boval et al., 2004) or predicting OM digestibility from feces (Lyons and Stuth, 1992; Boval et al., 2004; Franchone et al.,

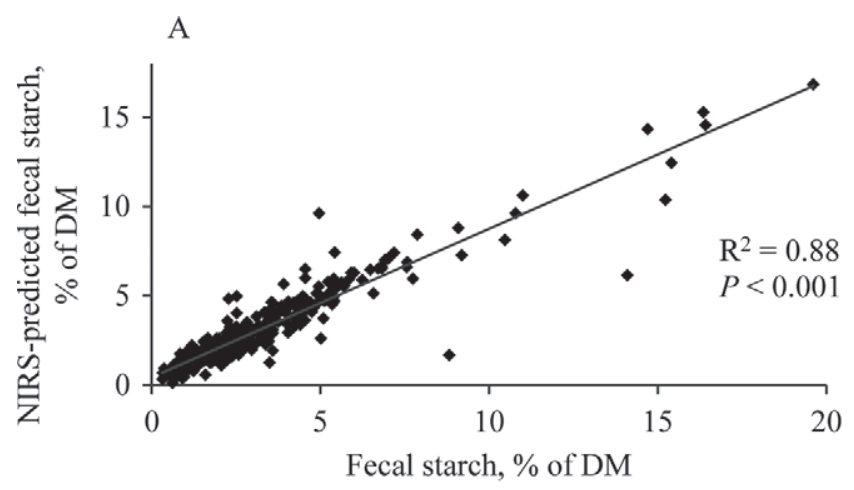

B

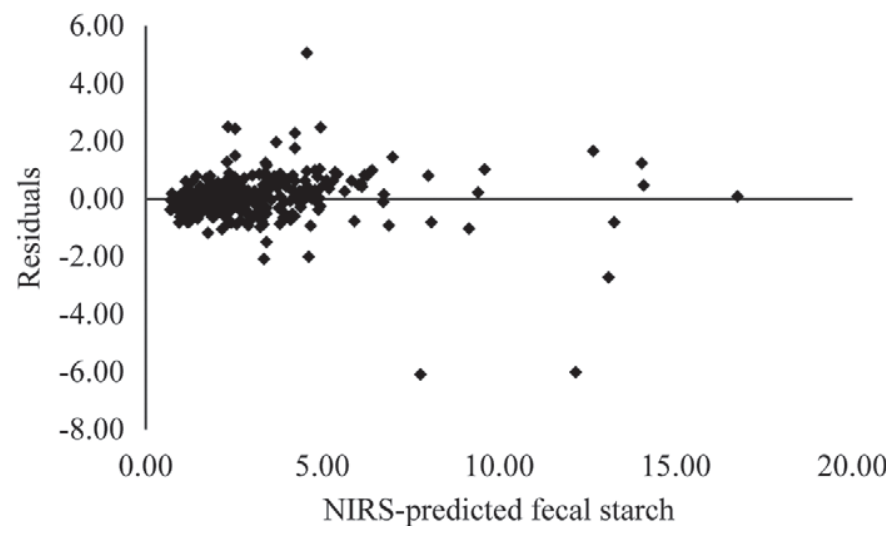

Figure 5. Regression plot of fecal starch content (\% of DM) determined by wet chemistry and near-infrared spectroscopy (NIRS). (A) NIRS-predicted fecal starch $\%=0.4( \pm 0.07)+0.83( \pm 0.02) \times$ fecal starch \%; root mean square error $(\mathrm{RMSE})=0.83, \mathrm{R}^{2}=0.88, P<$ $0.001, \mathrm{n}=335$; (B) plot of residuals: $\mathrm{Y}=0.00( \pm 0.05)+0.00( \pm 0.02)$ $\times(\mathrm{X}-2.99) ; \mathrm{RMSE}=0.83, \mathrm{R}^{2}=0.00, P=1.00, \mathrm{n}=335$.
2009) with moderate coefficients of determination $\left(\mathrm{R}^{2}\right.$ $=0.72-0.85)$. In total, the accuracy and precision of NIRS prediction of FS appears robust and would allow for a rapid and inexpensive measurement of FS for farm-level determination of TTSD. In fact, several commercial laboratories have recently begun offering NIRS-predicted FS.

\section{CONCLUSIONS}

Fecal starch concentration proved accurate as a predictor of TTSD by individual dairy cows in a series of controlled experiments where animals were fed corn silage-based diets. In addition, sampling day, week, or time within day had minimal influence on FS when TTSD was high. Because of the relatively minimal numerical differences on FS for sampling time within day, composites of fecal samples collected from multiple cows in pens once per day may provide a representative sample of feces for measuring FS. Based on measurements when TTSD was high, fecal $\mathrm{pH}$ was not reliable as an indicator of FS. Fecal starch concentrations can be accurately predicted by NIRS, allowing estimates of TTSD to be determined rapidly and economically. Fecal starch appears useful to monitor the TTSD of a ration to detect and subsequently alter rations with suboptimal TTSD. Diet alteration, in turn, should help to improve TTSD and efficiency of milk production.

\section{ACKNOWLEDGMENTS}

The authors thank Mike Peters and the staff at the University of Wisconsin-Madison Dairy Cattle Center (Madison, WI) and the Blaine Dairy Cattle Center (Arlington, WI) for animal care and trial management; Kevin Silveira (Department of Agronomy, University of Wisconsin-Madison) for technical assistance with 
NIRS software; and Fredric Owens (Pioneer Hi-Bred International Inc., Johnston, IA) for early review of the manuscript.

\section{REFERENCES}

Akins, M. S., K. L. Perfield, H. B. Green, S. J. Bertics, and R. D Shaver. 2014. Effects of monensin in lactating dairy cow diets at 2 starch concentrations. J. Dairy Sci. 97:917-929. http://dx.doi. org/10.3168/jds.2013-6756.

Arndt, C., L. E. Armentano, and M. B. Hall. 2009. Corn bran vs. corn grain at two levels of forage: Intake and production responses by lactating dairy cows. J. Dairy Sci. 92(E-Suppl. 1):94. (Abstr.)

Bal, M. A., J. G. Coors, and R. D. Shaver. 1997. Impact of the maturity of corn for use as silage in the diets of dairy cows on intake, digestion, and milk production. J. Dairy Sci. 80:2497-2503.

Bal, M. A., R. D. Shaver, H. Al-Jobeile, J. G. Coors, and J. G. Lauer. 2000a. Corn silage hybrid effects on intake, digestion, and milk production by dairy cows. J. Dairy Sci. 83:2849-2858.

Bal, M. A., R. D. Shaver, A. G. Jirovec, K. J. Shinners, and J. G. Coors. 2000b. Crop processing and chop length of corn silage: Effects on intake, digestion, and milk production by dairy cows. J. Dairy Sci. 83:1264-1273.

Barrière, Y., G. Dias Goncalves, J. C. Emile, and B. Lefevre. 2004. Higher intake of DK265 corn silage by dairy cattle. J. Dairy Sci. 87:1439-1445.

Boval, M., D. B. Coates, P. Lecomte, V. Decruyenaere, and H. Archimède. 2004. Faecal near infrared reflectance spectroscopy (NIRS) to assess chemical composition, in vivo digestibility and intake of tropical grass by Creole cattle. Anim. Feed Sci. Technol. 114:19-29.

Corona, L., S. Rodriguez, R. A. Ware, and R. A. Zinn. 2005. Comparative effects of whole, ground, dry-rolled, and steam-flaked corn on digestion and growth performance in feedlot cattle. Prof. Anim. Sci. 21:200-206.

Erdman, R. A., R. L. Botts, R. W. Hemken, and L. S. Bull. 1980. Effect of dietary sodium bicarbonate and magnesium oxide on production and physiology in early lactation. J. Dairy Sci. 63:923-930.

Erdman, R. A., R. W. Hemken, and L. S. Bull. 1982. Dietary sodium bicarbonate and magnesium oxide for early postpartum lactating dairy cows: effects of production, acid-based metabolism, and digestion. J. Dairy Sci. 65:712-731.

Fanchone, A., H. Archimède, and M. Boval. 2009. Comparison of fecal crude protein and fecal near-infrared reflectance spectroscopy to predict digestibility of fresh grass consumed by sheep. J. Anim. Sci. 87:236-243.

Fernandez, J. A., C. E. Coppock, and L. M. Schake. 1982. Effect of calcium buffers and whole plant processing on starch digestibility of sorghum based diets in Holstein cows. J. Dairy Sci. 65:242-249.

Ferraretto, L. F., P. M. Crump, and R. D. Shaver. 2013. Effect of cereal grain type and corn grain harvesting and processing methods on intake, digestion, and milk production by dairy cows through a meta-analysis. J. Dairy Sci. 96:533-550.

Ferraretto, L. F., and R. D. Shaver. 2012a. Effect of corn shredlage on lactation performance and total tract starch digestibility by dairy cows. Prof. Anim. Sci. 28:639-647.

Ferraretto, L. F., and R. D. Shaver. 2012b. Meta-analysis: Effect of corn silage harvest practices on intake, digestion, and milk production by dairy cows. Prof. Anim. Sci. 28:141-149.

Ferraretto, L. F., and R. D. Shaver. 2013. Effect of Bovamine on lactation performance by dairy cows. J. Dairy Sci. 96(E-Suppl. 1):11. (Abstr.)

Ferraretto, L. F., R. D. Shaver, and S. J. Bertics. 2012. Effect of dietary supplementation with live-cell yeast at two dosages on lactation performance, ruminal fermentation, and total-tract nutrient digestibility in dairy cows. J. Dairy Sci. 95:4017-4028.

Firkins, J. L., M. L. Eastridge, N. R. St-Pierre, and S. M. Noftsger. 2001. Effects of grain variability and processing on starch utilization by lactating dairy cattle. J. Anim. Sci. 79(E. Suppl.):E218E238.
Fredin, S. M., S. J. Bertics, and R. D. Shaver. 2013a. Effects of dietary starch content and corn particle size on intake, digestion and milk production by dairy cows. J. Dairy Sci. 96(E-Suppl. 1):149. (Abstr.)

Fredin, S. M., L. F. Ferraretto, M. S. Akins, and R. D. Shaver. 2013b. Effects of dietary starch content and NDF source on intake and milk production by dairy cows. J. Dairy Sci. 96(E-Suppl. 1):34. (Abstr.)

Gencoglu, H., R. D. Shaver, W. Steinberg, J. Ensink, L. F. Ferraretto, S. J. Bertics, J. C. Lopes, and M. S. Akins. 2010. Effect of feeding a reduced-starch diet with or without amylase addition on lactation performance in dairy cows. J. Dairy Sci. 93:723-732.

Grant, R. J. 2010. Lowering cost of production with feed efficiency and cow comfort. Accessed Nov. 18, 2013. http://www.centerfordairyexcellence.org/tl_files/CDE/PDF/08-10 Rick Grant presentation. pdf.

Gressley, T. F., and L. E. Armentano. 2005. Effect of abomasal pectin infusion on digestion and nitrogen balance in lactating dairy cows. J. Dairy Sci. 88:4028-4044.

Gressley, T. F., M. B. Hall, and L. E. Armentano. 2011. Ruminant nutrition symposium: Productivity, digestion, and health responses to hindgut acidosis in ruminants. J. Anim. Sci. 89:1120-1130.

Hall, M. B. 2002 Characteristics of manure: What do they mean? Pages 141-147 in Tri-State Dairy Nutr. Conf. Proc., Fort Wayne, IN. Michigan St. Univ., Ohio St. Univ., and Purdue Univ.

Hoffman, P. C., N. M. Esser, R. D. Shaver, W. K. Coblentz, M. P. Scott, A. L. Bodnar, R. J. Schmidt, and R. C. Charley. 2011. Influence of ensiling time and inoculation on alteration of the starchprotein matrix in high-moisture corn. J. Dairy Sci. 94:2465-2474.

Ireland-Perry, R. L., and C. C. Stallings. 1993. Fecal consistency as related to dietary composition in lactating Holstein cows. J. Dairy Sci. 76:1074-1082.

Kilmer, L. H., L. D. Muller, and T. J. Snyder. 1981. Addition of sodium bicarbonate to rations of postpartum dairy cows: Physiological and metabolic effects. J. Dairy Sci. 64:2357-2369.

Kilmer, L. H., L. D. Muller, and P. J. Wangsness. 1980. Addition of sodium bicarbonate to rations of pre- and postpartum dairy cows. J. Dairy Sci. 63:2026-2036.

Leonard, E. S., K. R. Pond, R. W. Harvey, and R. G. Crickenberger. 1989. Effects of corn grinding and time of corn feeding on growth, starch utilization and digesta passage characteristics of growing steers fed hay-based diets. J. Anim. Sci. 67:1603-1611.

Lopes, F., D. E. Cook, R. W. Bender, and D. K. Combs. 2013a. Effect of source of corn silage and level of dry matter intake on rumen nutrient sizes and turnover in dairy cows. J. Dairy Sci. 96(ESuppl. 1):523. (Abstr.)

Lopes, F., D. E. Cook, and D. K. Combs. 2013b. Effect of changing ratios of corn silage and alfalfa on ruminal fiber digestion in high producing lactating cows. J. Dairy Sci. 96(E-Suppl. 1):18. (Abstr.)

Lopes, J. C., R. D. Shaver, P. C. Hoffman, M. S. Akins, S. J. Bertics, H. Gencoglu, and J. G. Coors. 2009. Type of corn endosperm influences nutrient digestibility in lactating dairy cows. J. Dairy Sci. 92:4541-4548.

Lyons, R. K., and J. W. Stuth. 1992. Fecal NIRS equations for predicting diet quality of free-ranging cattle. J. Range Manage. 45:238-244.

Mentink, R. L., P. C. Hoffman, and L. M. Bauman. 2006. Utility of near-infrared reflectance spectroscopy to predict nutrient composition and in vitro digestibility of total mixed rations. J. Dairy Sci. $89: 2320-2326$

NRC. 2001. Nutrient Requirements of Dairy Cattle. 7th rev. ed. Natl. Acad. Sci., Washington, DC.

Nocek, J. E., D. G. Braund, and J. E. English. 1983. Effect of limestone reactivity and percent on production by dairy cows in early lactation. J. Dairy Sci. 66:2533-2543.

Owens, F. N., and R. A. Zinn. 2005. Corn grain for cattle: Influence of processing on site and extent of digestion. Pages 86-112 in Proc. Southwest Nutr. Conf., Tempe, AZ. University of Arizona, Tucson, and New Mexico State University, Las Cruces. 
Schwab, E. C., R. D. Shaver, K. J. Shinners, J. G. Lauer, and J. G. Coors. 2002. Processing and chop length effects in brown-midrib corn silage on intake, digestion, and milk production by dairy cows. J. Dairy Sci. 85:613-623.

Shenk, J. S., and M. O. Westerhaus. 1991a. Infrasoft International Software for Near Infrared Instruments. NIR Systems Inc., Silver Spring, MD.

Shenk, J. S., and M. O. Westerhaus. 1991b. Population definition, sample selection, and calibration procedures for near infrared reflectance spectroscopy. Crop Sci. 31:469-474.

St-Pierre, N. R. 2003. Reassessment of biases in predicted nitrogen flows to the duodenum by NRC 2001. J. Dairy Sci. 86:344-350.

Taylor, C. C., and M. S. Allen. 2005. Corn grain endosperm type and brown midrib 3 corn silage: Site of digestion and ruminal digestion kinetics in lactating cows. J. Dairy Sci. 88:1413-1424.
Wheeler, W. E., and C. H. Noller. 1976. Limestone buffers in complete mixed rations for dairy cattle. J. Dairy Sci. 59:1788-1793.

Wheeler, W. E., and C. H. Noller. 1977. Gastrointestinal tract pH and starch in feces of ruminants. J. Anim. Sci. 44:131-135.

White, H. 1980. A heteroscedasticity-consistent covariance matrix estimator and a direct test for heteroscedasticity. Econometrica 48:817-838.

Zinn, R. A., A. Barreras, L. Corona, F. N. Owens, and R. A. Ware. 2007. Starch digestion by feedlot cattle: Predictions from analysis of feed and fecal starch and nitrogen. J. Anim. Sci. 85:1727-1730.

Zinn, R. A., F. N. Owens, and R. A. Ware. 2002. Flaking corn: Processing mechanics, quality standards, and impacts on energy availability and performance of feedlot cattle. J. Anim. Sci. 80:1145-1156. 